\title{
An intellectual infrastructure for integrating design knowledge
}

\author{
Yusaku Shibata \\ Nagoya University of Foreign Studies \\ 57 Takenoyama, Iwasaki-Cho, Nisshin-city, Aichi 470-01, Japan \\ PH:+81-5617-4-1111, FX:+81-5617-5-1729 \\ E-Mail:shibatay@nufs.nakanishi.ac.jp and pxx11310@niftyserve.or.jp
}

\begin{abstract}
This paper analyzes the contradictions which hamper the collaboration of various stakeholders in evaluating early design concept, and defines a structural model of functional requirements for a team of catalytic consultants, which can facilitate self-organization of design knowledge and is named "SINPL-MEGANET".
\end{abstract}

\section{Keywords}

Architecture, catalytic coordination, design theory, evaluation, global sustainability, integration, knowledge, personal ity, purposeful action, self-organization, viewpoint

\section{INTRODUCTION}

If engineering artifacts should be reconciled with aspects of future world, the basic question is whether the effort toward improving the competitiveness of each company, which is the main item of interest in today's liberal economy, contributes correctly to the improvement of global sustainability. (Reich 1991, Yoshikawa 1993) The design process is a central research issue in responding to this question, which requires a change in the context of design from a short term market oriented industrial Product Realization Process (PRP) to a longer term global societal Artifact Utilization Process (AUP). This change implies that we must learn to design artifacts while concurrently, not only designing the manufacturing system, but also planning for the associated socio-technological system in which the artifacts will be utilized during their life-cycles. It inevitably extends the concept of design teams from business-oriented "cross-functional" teams to intellectually "multi-cultural" teams of sociologists, economists, scientists, engineers, business people, lawyers, theologians, and no doubt others, for whom the key design issue will be in the evaluation steps of guided iteration. (Dixon 1993) It also necessitates extending the concept of enterprise to the extended enterprise or the "Global 
Web" consisting of "Symbolic Analysts". (Reich 1991)

In response to these challenges, the call for papers of the second workshop on "Knowledge Intensi ve CAD" (KIC-2) reads:

"Due to the increasing concern about global environmental issues and rapidly changing economical situation worldwide, design must exhibit high performance not only in quality and productivity, but also in life-cycle issues, including extended producer's liability.....The concept of 'knowledge intensive engineering' advocates that intensive life-cycle knowledge regarding products and design processes must be incorporated in the center of the CAD architecture. The concept focuses on the systematization and sharing of knowledge across the life-cycle stages and organizational boundaries."

From 1953 to 1991, the author had been engaged in artifacts engineering activities, initially as a manager of steam turbine design engineering and later as a senior systems researcher of large scale artifacts development process, such as alternative energy systems and new transportation systems, both at a diversified manufacturing company named Hitachi, Ltd. From 1991 to 1996 as a university professor and a member of an international task force, he has analyzed his life-long experience and synthesized the result into a concept of intellectual infrastructure for integrating design knowledge as described in this paper.

\section{CONTRADICTIONS}

As quoted above from the call for KIC-2 papers, "the concept (of knowledge intensive CAD) focuses on the systematization and sharing of knowledge across the life-cycle stages and organizational boundaries." In other words, the "knowledge intensive CAD" should assist various practicing managers and professionals in systematizing and sharing knowledge required to plan and evaluate the Artifact Utilization Process, especially at the initial stages of systems development. However, design knowledge can be integrated not only by CAD systems, but also by the participation of people with various cultural backgrounds, who have very different types of personality and hence, viewpoints. Thus, design is a social process as well as an engineering process.

It should be noted that bringing various specialists together does not insure that knowledge about making design decisions will also be available. A distinction must be noted between the specialist's analytical knowledge of a life-cycle issue and the practitioner's integrative capability for creating and modifying early design concepts so that the life-cycle concerns are resolved. One of the most crucial elements in this process is the ability for groups to exchange models, data, information, and knowledge. For this to happen, the participants must synthesize and formalize much of the knowledge that is currently shared informally. (Finger 1993, Reich,Y. et al. 1996)

A reason for our failure in Artifact Utilization Process is the lack of understanding and agreement about the contradictions which hampered the integration of and the consensus building between various viewpoints into deeply structured, easily adaptable and comprehensive conceptual models. Figure 1 shows a relational structure of obstacles which was identified originally in the development of new energy technologies but later found to be applicable as a generic structure to other collaborative systems developments. (Shibata 1984, 1993) In order to integrate various systems development activities across the life-cycle stages and organizational boundaries, we should strive to achieve a pro-active, aware extended 
enterprise which is able to act in a realtime adaptive mode, responsively to the societal needs in a global way, and to be resilient to changes in the technological, economic, and social environment. Therefore, the enterprise integration, or the objective of knowledge intensive CAD is strategic as well as technical.

For example, the IFAC/IFIP International Federation of Automatic Control and International Federation for Information Processing) Task Force on Architectures for Enterprise Integration, of which the author is a member, early recognized that a

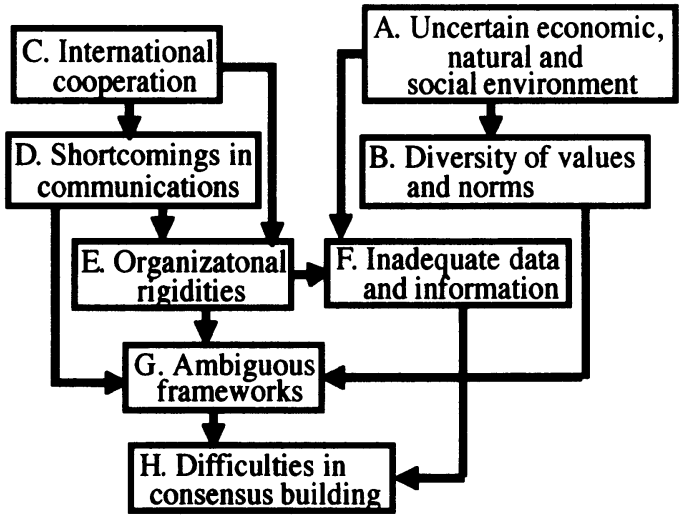

Figure 1 Relational structrue of obstacles in collaborative systems development. (Shibata 1993) single, universally accepted architecture would be a major contribution to the field of enterprise integration. However, although the group first tried the path of finding an acceptable candidate from among those currently available and then extending it as necessary for their purpose, they have failed in this for political rather than technical reasons and resolved that only requirements and definition of a new architecture should be developed from the best characteristics of the set of existing architectures being studied by the Task Force. (Williams and $\mathrm{Li} 1995$ )

Having accomplished this target, a next step of the Task Force is the development of the Enterprise Integration Community that will use and expand the requirements and the definition of the new architecture. Another next step is to create an infrastructure composed of Web Sites in the USA, Australia and Europe to promote the enterprise integration and to refine the Generalized Enterprise Reference Architecture and Methodology (GERAM). "Such an electronic community can increase in scale only if the community shares its resources to build continually on the work of each participant not only for the creation of architectures for enterprise integration but also for the infrastructure itself.....In systematizing the knowledge about the life-cycle of manufacturing enterprises, it is essential to keep in mind the purpose for which the knowledge is being acquired. (Finger 1993, italics paraphrased)"

Thus, the goal of knowledge intensive CAD should be threefold: to provide information and tools for knowledge intensive design, to assist the transformation and integration of enterprises into the extended or virtual enterprises, and to develop and maintain a new intellectual infrastructure for enterprise integration, composed of both human and electronic communities.

\section{KNOWLEDGE AND PURPOSEFUL ACTION}

Curiously enough, we have been unsure about design theory. We have argued whether there could be a theory of design, what form it would take, and how it would relate to practice. We have never resolved these issues to the satisfaction of our professional community or even to the satisfaction of those, mainly in design education, who worry about the state of theory in 
design. The recognition that the traditional design theory might be wrong came through the widening gap between academic knowledge of scholars and action of practitioners. On the other hand, invariably at the core of professionalism is the assumption that professional action is and should be guided by knowledge. This professional knowledge, however, in contrast to academic knowledge, is primarily derived from action which is in no sense neutral-- it is grounded in intentions or aims of the actor. Thus, acts of design belong to the category of behavior called teleological, i.e., "goal seeking" behavior. (Ozbekhan 1974)

There are two senses of design, one that we acknowledge and one that generally we do not acknowledge. Most readily, design is understood in terms of tangible things or shape, for example automobiles, computers, clothes, furniture etc. We are less likely to use the word in its process meaning--putting concepts and ideas into material action, requiring the deep and often tacit knowledge--between individuals--goes largely unacknowledged. However, design in its planning meaning is, interestingly, the first meaning of the word in the Complete Oxford English Dictionary. The effect of this category mistake in design is to make the planning sense of early design concept silent, hence to place a ghost in design process, which defies explanation and hampers deep understanding of design process and hence, of underlying contradictions. (Ryle 1949, Koestler 1967 and Dumas 1993)

Since our goal is to improve the design process of artifacts, we must systematize the knowledge in such a way that it is usable by designers to aid themselves in making design decisions. "This knowledge is at present the kind that has been accumulated within companies and acquired through systematized experience yet. It should now be systematized through post-competitive research. This empirically acquired knowledge, as al ready stated, is created through competition by companies; the art of creating it is known theoretically, as abduction (Yoshikawa 1992). At present, there is virtually no field of research or researchers devoted to abduction itself. What is needed now is to set this act as a topic of study and to organize postcompetitive research that will involve various studies including the development of new research technique. (Yoshikawa 1993)"

Bolan (1980) has al ready explored the gap between two kinds of knowledge--academic and professional, and the resulting chasm between knowledge and action. In his paper, after examining the distinction between the logic of scientific knowledge and the logic of practice, he analyzes, as shown in Figure 2, the practitioner $(X)$ as a "self-in-situation," suggesting that designing episodes are analogous to dramas, and reflect the existing of the designers $(X)$ in scenes with constituent others ( $\mathrm{Y}$ and $\mathrm{Z}$ ), each of whom mutually constructs a performance, conforming in some degree to the symbolic codes and norms of the situation.

Figure 2 attempts to describe the realm of consciousness that is guiding the practitioner. He apprehends a situation and makes judgments which lead to a series of assumptions concerning self, others, and circumstances. The full dimensions of a scene, as actually presented to us, enter into our consciousness, and we screen the $m$ with our various sense faculties--some features high-lighted, others become part of a background. Thus, we each operate with very diffe rent sensitivities and viewpoints. In this connection, personal ity types of practitioners (X, $\mathrm{Y}$ and $\mathrm{Z}$ in Figure 2), as "selves-in-action", will be considered in the next section.

\section{PERSONALITIES AND VIEWPOINTS OF PRACTITIONERS}

As described in the previous section, Figure 2 "depicts the professional episode. The term 'episode' is defined to include all of the persons involved, the situations or scenes involved, and the interactions of persons and settings as they are focused on a specific problem or 


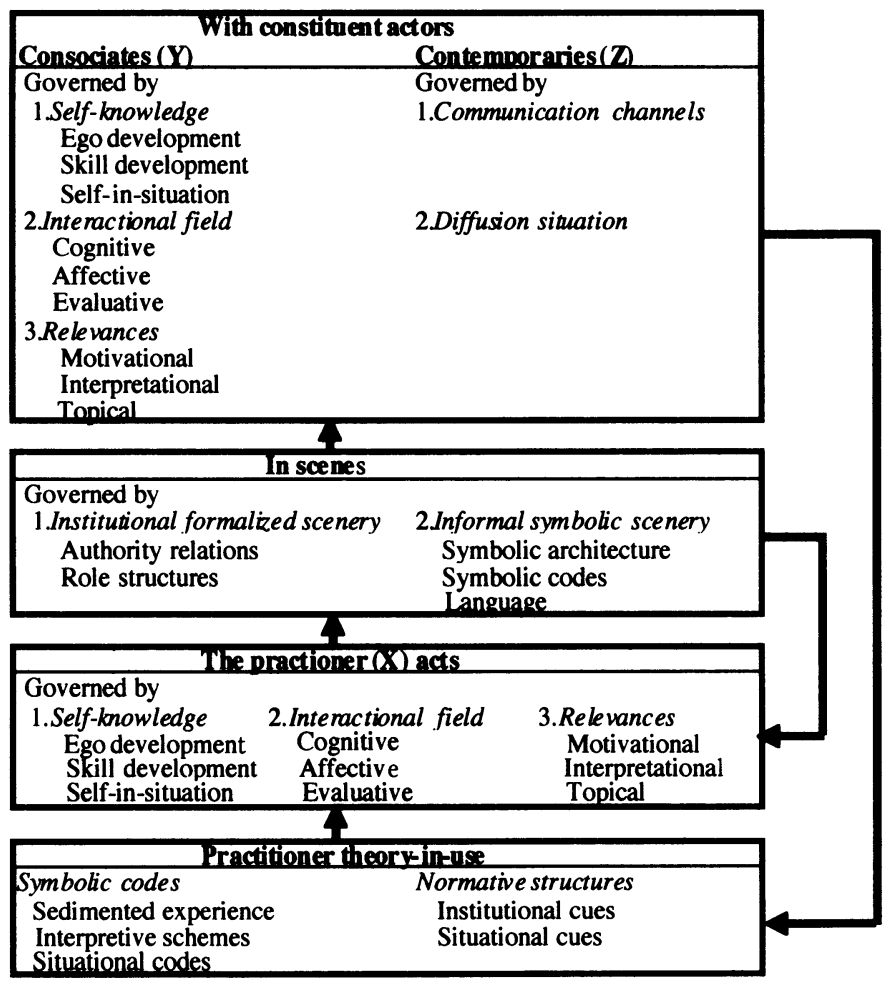

Figure 2 Elements of the professional episode. (Bolan 1980)

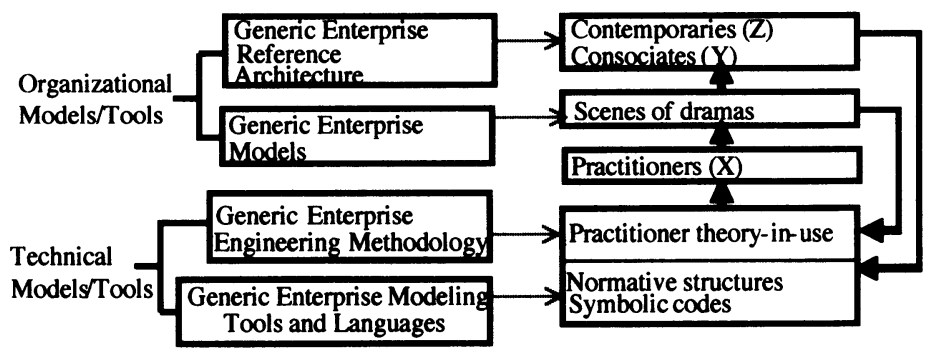

(A)Components for the Generalized

(B) Activity model of enterprise Enterprise Reference Architecture and Methodology (after Williams et al. 1993) engineering (after Bolan 1980)

Figure 3 Correlation between reference architecture and integration activity. 
intention A designing episode is conceived as consisting of a series of situations and scenes, not unlike a drama. However, there is no master playwright assumed; such episodes are more analogous to improvisational theater. There is no ultimate determinism implied; the participants are relatively free to define their own actions and make their own choices. Some episodes may be confined to a single scene, some may extend to many scenes of very diverse character. What binds them together into a single episode is the intentionality or problem orientation of the participants. (Bolan 1980)"

Because the beneficiary of knowledge intensive CAD is design teams composed of "multicultural" professionals--for whom the key design issue is in the evaluation steps of early design concept, the CAD system must be understandable and usable by the multidisciplinary participants with various viewpoints in dynamically changing situation as described above, in addition to a technical correctness and a practical comprehensiveness. In other words, it should be developed and maintained based upon proper understanding of predicaments confronting multi-cultural participants under contradictory situations, or based upon a reasonable framework of designers' evaluation.

Mitroff and Kilmann (1975) have suggested a framework whereby the personality types which underlie various modes of evaluation may be identified and thereby themselves be evaluated Their paper made clear why there were no evaluation frameworks which had attempted to combine these various personal ity types into a coordinated whole. The difficulty for them is how to reconcile radically distinct, and sometime hostile, psychological viewpoints and exchange models and knowledge for integration.

The personality typology suggested by Mitroff and Kilmann was "that of C. G. Jung. The Jungian typology was used for two reasons: (1) the typology can be directly related to different styles of doing technological evaluation; and hence, it allows us to compare these styles in an interesting manner; (2) the Jungian typology does not prescribe one of the four major personality types as superior or inherently better than any of the others but instead points out that each type has its major strengths as well as weaknesses.

For the purpose of this paper, two particular dimensions of the Jungian typology are of special importance. The first dimension corresponds to the kind of 'input-data' an individual characteristically prefers to take in from the outside world. The second dimension corresponds to an individual's preference for the kind of 'decision-making process' that he characteristically brings to bear upon his preferred kind of input-data.

According to Jung individuals can take in data either by sensation (S) or by intuition (N) but not by both simultaneously. On the other hand, there are two basic ways of reaching a decision: thinking $(T)$ and feeling $(F)$. Combining the two data input modes ( $S$ and $N$ ) with the two decision making modes ( $\mathrm{F}$ and $\mathrm{T}$ ), as shown in Figure 4, results in the following four types:"

(ST) sensation-thinking (technology oriented),

(SF) sensation-feeling (organization oriented),

(NT) intuition-thinking (concept oriented), and

(NF) intuition-feeling (culture oriented).

However, by the notion of different "types", Jung does not mean to imply there are literally "four basic kinds of people and that each person is one of these and one only". Rather, he merely means to imply that these four types help us to come to grips with the elusive problem of handling different styles of

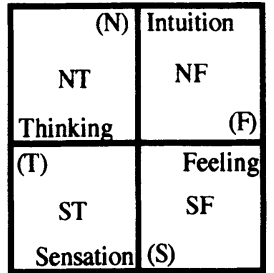

Figure 4 Personality types. (Mitroff et al. 1975) 
behaving With this condition attached, followings might be typical viewpoints of various personality types on the Artifact Utilization Process. (Mitroff et al. 1977)

\subsection{ST Type (technology oriented)}

"ST types generally tend to prefer, and hence to generate, ideas which are highly detailed and specific and which overwhelmingly deal with technical issues in an impersonal way. In a word, ST's are problem-solvers, i.e., they prefer to work on very concrete, very specific, al ready-defined pre-existent technical problems. They are neither problem-finders nor problem-generators, nor are they especially sensitive to personal, moral, or value issues. Indeed, one of the strong defining characteristics of ST's is that they believe that moral or ethical issues are either meaningless in themselves or devoid of substantive precisely because they cannot be formulated precisely, impersonally, and technically, or at least not to the satisfaction of ST's." For example,

"Since many of these problems (modern evils) result from the use of existing technologies, the solution to these problems will depend in large part on the development of new technologies in addition to policies which encourage behavioral change.....(Although) individual technological development for new types of artifacts,....is necessary, including design, production, operation, maintenance, reclamation, reuse, recycling, and discarding.....we point out that knowledge systematization over life cycle stages is the most urgent task. (Tomiyama 1993)"

\subsection{NT Type (concept oriented)}

"NT Types generally tend to prefer ideas which are highly global, broad, far-reaching, and which deal with a wide range of overwhelming technical issues in an impersonal manner. In a word, NT's are problem-inventors, problem-finders, or problem-generators. They prefer working on the new and innovative to the tried and true. Like their ST counterparts, they tend to be insensitive to personal, moral, and value issues. This is not so much because they feel moral issues are meaningless unless they can be formulated in detailed specifics (indeed, unlike ST's, they are not interested in the details of issues, but rather with their over-all or holistic features); rather, it is because NT's are more interested in technical ideas than they are in people." For example,

"We cannot build it yet. But al ready we can specify the 'postmodern' factory of 1999. Its essence will not be mechanical, though there will be plenty of machines. Its essence will be conceptual-the product of four principles and practices that together constitute a new approach to manufacturing. (Drucker 1991)"

\subsection{NF Type (culture oriented)}

"Like NT's, NFs also tend to take a global approach to issues and problems. This is due to the common $\mathbf{N}$ or intuitive side of their personality which they share. The essential difference is that where NT's are primarily interested in treating all matters from an impersonal or technical point of view, NFs are primarily interested in treating them from a personal, human, moral, and ethical point of view. For NFs people are the overriding concern. Like NT's, NF's are also problem-generators. However, the difference is (again) that NFs are problem- 
generators of people problems. All problems are, for them, in the first and last resort people problems. " For example,

"The liberal economy must begin to move toward seeking optimum suitability by itself because it is clear that today's liberal economic system is not optimal, at least from the standpoint of global reduction of waste....Intelligent Manufacturing Systems (IMS) is a technical cooperation for the ideal theory of manufacturing that transcends cultural differences....IMS is a dream, and please join us for realizing our dream. (Yoshikawa 1993)"

\subsection{SF Type (organization oriented)}

"SF's are like ST's in their strong liking and preference for specificity, detail, and wellformulated problems. Like ST's, they tend to be problem-solvers rather than problemgenerators. They differ, because of the $\mathrm{F}$ component of their personality, in their preference for people. For SF's, as for NF's, people are always the overriding concern. The main difference is that where NFs like people in general humanity, SFs like people in particular, i.e., their immediate circle of friends, associates, neighbors, etc. Anything which fails to relate directly and specifically to their immediate circle of friends is either irrelevant or meaningless. Another way to put it is to say that they find abstract, theoretical, and scientific solutions utterly cold, impersonal, and meaningless." For example,

'The future will neither belong to 'big' and 'intelligent' technology, nor to 'large' and 'powerful' bureaucracies, but to human organizations that will be able to set up human goals shared by the largest as possible fraction of people throughout the world, and to achieve them by using knowledge and technology, in the public and general interest. (Petrella 1989)"

\subsection{Integrating Different Personalities and Viewpoints}

As described above, the key research issue of Artifact Utilization Process lies in the evaluation steps at the early planning phases. But, it should be clear by now that in integrating design knowledge and activities, we are dealing with very different types of individuals who find extreme difficulty in appreciating one another. However, a point of particular interest is the fact that all of four Jungian types are valuable and needed in planning, but at different stages of planning. Thus, N's are better suited at the strategic phase of planning, whereas S's are better suited for translating strategic ideas into operational plans. Both need as well as depend upon one another. Therefore, our next task is to find a proper framework and a calalytic coordination system for a self-organized integration of design knowledge and activities, which will be dealt with in the following sections.

\section{A FRAMEWORK FOR INTEGRATING DESIGN KNOWLEDGE}

\subsection{Architectures and Frameworks in Integrating Design Knowledge and Activities}

The integration of design knowledge requires inevitably the integration of various engineering activities within an extended enterprise, which does not occur without a fundamental transformation in business structure and process. (Inagaki 1993) The primary challenge for the enterprise is to maintain relevance in the face of a dynamic marketplace and dramatically 
changing technologies. When the transformation is not effected by ourselves, the result is early obsolescence and a control of our destiny by someone else. "Social architecture is the art of designing and building a complex organization. Welch characterizes his vision for the next century with the word 'boundarylessness'. 'Old Way' organizations were all about boundaries and compartmentalization and chains-of-command. The new organization would be free of these increasingly nonproductive strictures. Information would flow freely across functional and business boundaries from where it was developed to where it was needed. (Tichy and Sherman 1994)"

James G. Nell (1996), Convener of the International Standards Organization(ISO)/ TC184/SC5/WG1(Working Group 1: Modeling and Architecture) has proposed followings as the WG1 definition of architecture and framework

\section{Architecture, or Enterprise-Reference Architecture \\ The body of classified knowledge for designing, building, operating, and modeling enterprises. The architecture contains guidelines and rules for the representation of the enterprise framework, systems, organization, resources, products, and processes.}

\section{Framework}

The delineation of the components and viewpoints (for example: activity, information, and process capability) that comprise a specific enterprise representation, the interfaces, and the relationships that exist between the respective viewpoints of the components.

According to Nell (1996), a shared-meaning element between architectures and frameworks is an arrangement. "The life-cycle activities of a system development during which an arrangement becomes available, occurs toward the end of the system-definition activities and toward the beginning of the physical-realization activities. This is where the physical arrangement aspect of architecture and the structural arrangement aspect of framework converge. Given this, to define framework one may assume, therefore, that there exists a relevant architecture. This architecture, among other things, define a framework--the limiting structure and its supporting members--of the thing being built. The framework is the defining real-world manifestation of a portion of the abstract notion of architecture. A framework is a basic structure; a frame of reference, or a systematic set of relationships. The framework does not include the art, science, style, and methodology required to develop the system, only the scope of the system and an arrangement of the components, standards, or principles governing behavior, thoughts, actions....The choice of framework depends on the purpose of the endeavor. Thus, architectures supply the body of topical facts and knowledge, and frameworks define the scope, the interface and the components."

The IFAC/IFIP Task Force on Architectures for Enterprise Integration has found that the concept of architecture for enterprise integration is beginning to have coherence and has principally four main components:

OGERA (Generic Enterprise Refe rence Architecture);

GEMs (Generic Enterprise Models);

GEEM (Generic Enterprise Engineering Methodology);

GEMT\&L (Generic Enterprise Modeling Tools and Languages),

and supporting sub-components as shown in Figure 5, which were named GERAM (Generalized Enterprise Reference Architecture and Methodology) as a collective term. ISO/TC184/SC5/WG1 is now starting to discuss GERAM as a new-work-item proposal. 


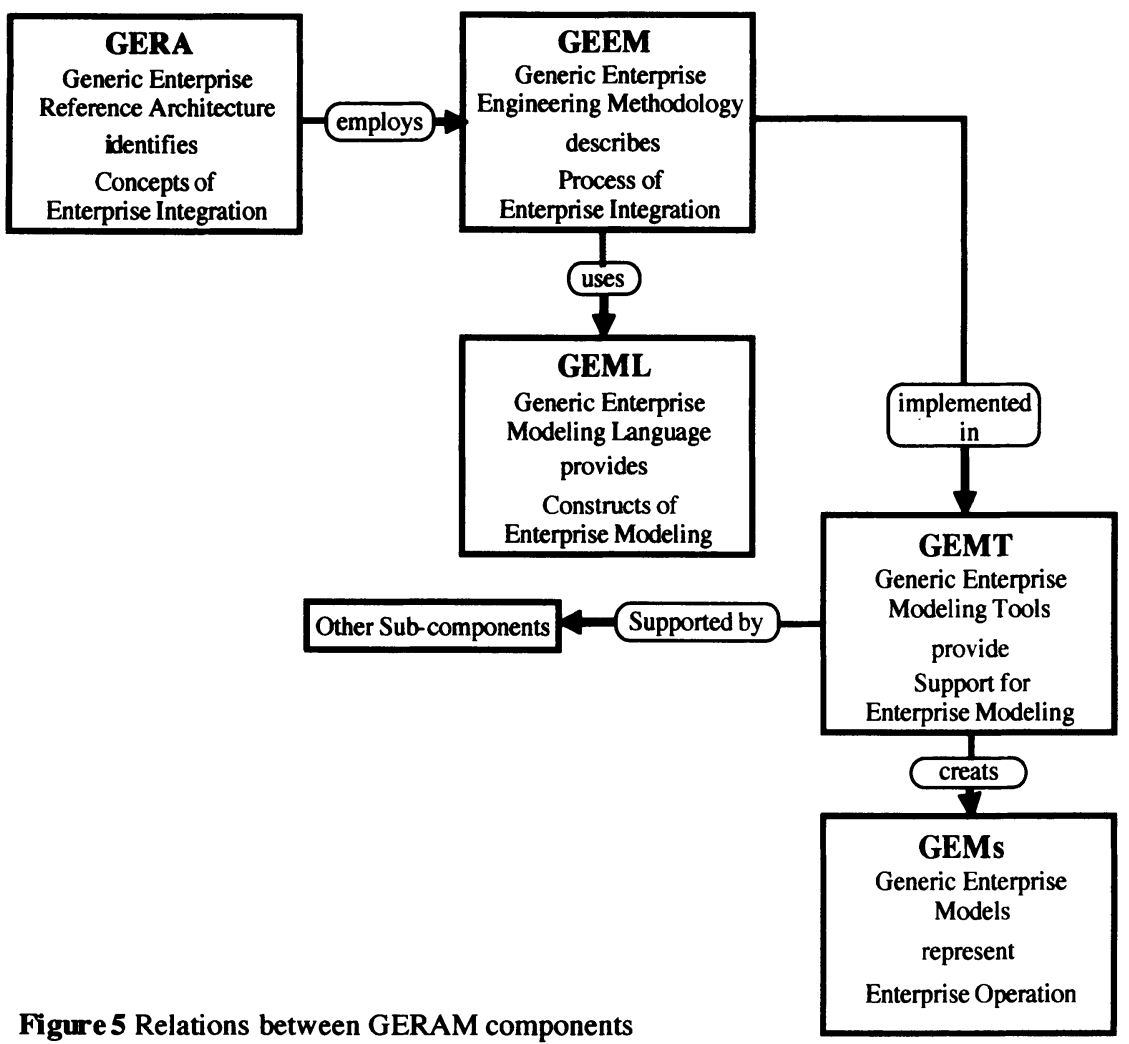

In addition, the task force believes that the same architecture can be used to describe not only the enterprise integration process itself, but also three other related enterprise activities as well:

Strategic enterprise management process life cycle;

Enterprise engineering/integration process life cycle;

Enterprise life cycle;

Product life cycle.

"Such a concept of universal usage of the principles of enterprise reference architecture applicability in all areas of human endeavor today has major ramification on the importance and potential future use of the result of the IFAC/IFIP Task Force's work. (Williams 1994)" For the moment, such a development remains open ended. Nevertheless, its overall configuration, its main concepts and phases, are now sufficiently general so that one can describe and discuss them without specific cases. The purpose of this paper is precisely to do that in the area of Artifact Utilization Process life-cycles and to propose a new framework, as defined below, for the purpose of enterprise extension and transformation 


\subsection{Requirements for a Framework for Artifact Utilization Process Life-Cycle}

Quoting again and paraphrasing Nell's definition of framework as described in the previous sub-section, "the framework should be the defining real-world manifestation of a portion of the abstract notion of GERAM. The framework should be a basic structure of artifact utilization process life-cycle; a frame of reference, or a systematic set of relationships. The framework should not include the art, science, style, and methodology required to develop the system, only the scope of the artifact utilization process life-cycle system and an arrangement of the components, standards, or principles governing behavior, thoughts, actions....The choice of framework depends on the purpose of the endeavor, which is an enterprise transformation for Artifact Utilization Process."

In developing a framework for Artifact Utilization Process life-cycle, we should consider carefully Bolan's suggestion on the professional episode, especially the roles of actors as "selves-in-action" as shown in Figure 2. For example, in order to be a useful guidance system in practice, four components of GERAM as shown in Figure 3(A) should be interfaced with the activity model as shown in Figure 3(B), which was derived from Figure 2. From the same standpoint, the author is proposing a framework consisting of four components as described in the following sub-sections:

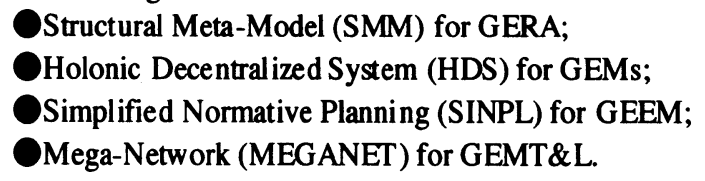

\subsection{Structural Meta-Model (SMM) for GERA}

Pilot case studies of CIMOSA (CIM Open System Architecture), which is one of three candidate architectures of GERAM, have shown that the most striking potentials today lay in the field of organization. Starting from the traditional Tayloristic understanding of the enterprise, many iterative steps were necessary to arrive at the changement of thinking, which needed a period of learning by doing and some doubts and crises under way for all of the team. The only recently defined constructs for the organization view proved to add an important amendment to the architecture that so far has been very much information technology oriented. At present, specific tools to apply enterprise models unfortunately do not exist. They will simplify modeling and augment user acceptance. (Katzy et al. 1993)

Above mentioned issues require more simplified modeling tools, especially laying emphasis on organizational redesign Managers and professionals, who are engaged in enterprise transformation, must overcome many obstacles, both technical and nontechnical, as shown in Figure 1. Their actions will possibly become more effective if relevant information and guidelines are timely offered to them based upon some reliable design theory. However, we are unsure about a reliable design theory because, al though there has been increasing criticism of the ruling design theory, no set of concepts has emerged that convinces a majority of practitioners that the new paradigm of design theory has been found.

In the following sections, an emerging design paradigm is leading to the redefinitions of design process model, in which Figure 1 will suggest relations between the enterprise and its environment, and will be utilized as a graphical expression of a framework, named Structural Meta-Model (SMM). SMM includes the enterprise model implicitly as a subsystem which will be a Holonic Decentralized System (HDS) and dealt with briefly in the next sub-section. 


\subsection{Holonic Decentralized System (HDS) for GEMs}

The enterprise transformation can not be imposed as a rigid regimen. It is dynamic, built around the requirements of autonomous subsystems, continuously evolving and responding as the situation changes. Throughout the entire process, cooperation among all participants in the decision making stages and integration of each subsystem's requirements into the process are essential factors. By identifying in advance the interfaces of extended enterprise as it is shaped by and affects the different parts of Artifacts Utilization Process, we can improve the efficiency and the effectiveness of transformation process, which will permit operations to be made concurrently.

Some 25 years ago, Koestler (1989) has proposed a word "holon" to express a similar concept on social structures and functions. The word is a combination from the Greek holos (=whole) with the suffix on, which suggests particle or part. He points out that in this system, the subwholes/holons are autonomous self-reliant units, which have a degree of independence and handle contingencies without asking higher authorities for instructions. Simultaneously, holons are subject to control from multiple higher authorities. The first property ensures that holons are stable forms, which survive disturbances. The latter property signifies that they are intermediate forms, which provide the functionality for the bigger whole. Kurosu of Toyota (1992) wrote that the essence of Toyota production system is the holonic system which is defined as "a system composed of essentially distributed elements which act and cooperate with each other based on autonomously selected individual norms in order to achieve individual objectives". HDS is proposed as a model system and describes the integrated enterprise as it is going to function.

\subsection{Simplified Normative Planning (SINPL) for GEEM}

As described in section 3, the discussion of design theory appears to be stuck and in need of renewal It is stuck in that the criticisms of the rational design model and proposals of alternatives to it continue to repeat the same arguments and draw familiar ideas. Meanwhile, indifference and hostility of practitioners to researchers of design theory grow. This suggests that we need to simultaneously pursue a search of new framework for cooperation between practitioners and researchers and a research of design model building itself.

Simplified Normative Planning (SINPL) as shown in Figure 6 seems to be one of methodologies ideally suited for catalyzing a self-organized modeling process. (Shibata 1992) The goal of SINPL is primarily to define the framework of design or to meta-design. The difficulty of meta-design will be alleviated to some extent by using a conceptual framework

\begin{tabular}{|l|l|l|}
\hline Soft methodology (Checkland 1981) & SINPL (Shibata 1992) & Welch (Tichy 1994) \\
\hline 1. Expressed problems & Future Scenario & Prologue \\
\hline 2. Root definition & Insight of contradictions & Awakening \\
\hline 3. Conceptual model & Normative objectives & Envisioning \\
\hline 4. Possible solutions & Strategic Plan & Rearchitecting \\
\hline 5. Action plan & Launching tactics & Epilogue \\
\hline
\end{tabular}

Figure 6 Five steps models of design process by various authors. 
(meta-rule) of SINPL which consists of design process (meta-process model), problem structure (meta-problem model) and players team organization (meta-role model). A special feature of SINPL is that it does not start from a given problem but from a desirable future vision or a norm, from which the name SINPL is derived. Also S-I-N-P-L explains five workshop steps as described below:

1. Forecasting desirable future (process) and vision $\underline{\text { Scenario (structure) }}$

2. Insight of contradictions (process) and problem structure (structure)

3. New idea proposal (process) and Normative objectives (structure)

4. Strategic Planning (process) and strategic patterns (structure)

5. Action proposal (process) and Launching tactics (structure)

The chief advantage in using SINPL for complex problem solving is that they provide a mode of experimentation with alternative strategies and tactics in a constantly changing environment. The fluid nature of a meta-design approximates the uncertainties encountered in a real situation. The artificially controlled contexts, which the conceptual framework of a meta-design imposes, build into it certain relationship between the decisions made by some of the players and the response of other stakeholders. But these relationships are unknown initially to the players and are only revealed as the meta-design proceeds. So the outcome of a particular decision or strategy has immediate effects, thereby providing data for analyzing and evaluating the selected course of action with neither the time lag nor the potentially irreversible consequences of a decision in the real world.

\subsection{Mega-Network (MEGANET) for GEMT\&L}

The artifact utilization and enterprise transformation process is a highly sophisticated, multidisciplinary management, design and implementation exercise during which various forms of descriptions and models of the target process need to be created. In addition to a technical correctness and a practical comprehensiveness, GEMT\&L (Generic Enterprise Modeling Tools and Languages) should be understandable and usable by the communities targeted Quoting and paraphrasing Nell's definition of framework (1996) again, "the framework should be the defining real-world manifestation of GEMT\&L--a portion of the abstract notion of GERAM". Two main objectives of the framework for GEMT\&L are for all participants to understand the real world meaning of artifact utilization and enterprise transformation process, which will not start spontaneously with no external intervention and coordination. The capacity to sustain such massive coordination over a long period of time and retain the stability of policy throughout the process, is the basic requisite of complex problem solving. Sustained drive and energy, as well as the creative catalytic leadership style, are scarce skills within our society and the third objective of the framework.

Thus, a new conceptual and essential scheme to aid this endeavor is a framework named MEGANET (Mega-Network), which means "a network to support formation of conceptual strategy or policy" and is a network or a global web of extremely creative catalytic consultants and can be utilized to help managers and professionals solving obstacles in the enterprise transformation process. (Shibata 1984)

Howe ver, for sometime to come, the framework can not be a guidance system but should be a social learning environment because the barriers between professionals cannot be removed by a framework and/or advice from outside consultants. The main requirement is that the persons concerned with interprofessional collaboration become so well acquainted with each other's viewpoint that the mutual misunderstanding of specialists is replaced by overlapping vievs. Therefore, an essential task for the framework in this endeavor is the creation of 


\begin{tabular}{|c|l|l|}
\hline Steps & \multicolumn{1}{|c|}{$\begin{array}{c}\text { (5.5 ) SINPL for GEEM } \\
\text { (Shibata 1992) }\end{array}$} & \multicolumn{1}{c|}{$\begin{array}{c}\text { (5.6) MEGANET for GEMT\&L } \\
\text { (Shibata 1984) }\end{array}$} \\
\hline 1 & Future scenario (S: Why?) & Intellect on future and viewpoints \\
\hline 2 & Insight of contradictions (I: However) & (5.3) SMM for GERA \\
\hline 3 & Normative objectives (N: What?) & Intellect on policy formation \\
\hline 4 & Strategic plan (P. How?) & (5.4) HDS for GEMs \\
\hline 5 & Launching tactics (L: O.K.) & Intellect on resources and technologies \\
\hline
\end{tabular}

Figure 7 Interrelationships between MEGANET and other components of a framework for GERAM

learning environment and process which allow specialists and managers as well as customers to self-organize a shared framework of system appreciation and facilitate the renewal of design theory.

Thus, MEGANET is like a catalyst because it guides the change process with no external power or authority. It is also similar to a gene. MEGANET itself is autonomously decentralized and has all fundamental functional units necessary for the target systems. In this meaning, it is a model which has a good communication capability with the client. However, the target system is not a physical, chemical nor biological phenomenon, but is a social phenomenon composed of many people and can creatively evolve forever. What guarantees this evolution is an extraordinary capability of the system to communicate with surrounding environment. Another capability which is indispensable to maintain the unity and harmony of the system is an attractive common vision which should be, again, self-organized.

From the preceding discussions, it is clear that MEGANET--the concepts of which were originally proposed by Friedmann (1973) and Williams (1973) and modified by Shibata (1984)--must play a variety of roles with respect to the obstacles facing transformation as shown in Figure 1. However, because the obstacles are highly interdependent, the framework of K!EGANET cannot be such that there is only one function for each obstacle. Rather, the framework that should emerge is a mix of functions to deal with multiple obstacles and interrelationship at the various le vels of management as shown in Figure 7.

\section{CONCLUSION: TOWARD AN INTELLECTUAL INFRASTRUCTURE FOR INTEGRATING DESIGN KNOWLEDGE}

Based upon his life-long experience as a practicing design engineer at a manufacturing company and a researcher at universities, the author believes that a framework composed of four components as described above is an insightful conceptualization of enterprise transformation for artifact utilization process. It both highlights critical issues and guidelines for integrating extended enterprise where autonomously decentralized organizations and individuals should be interfaced. It further suggests group processes and agenda formats which guide each step of enterprise transformation.

From a number of experimental and preliminary applications of this framework, which was named SINPL-MEGANET, the author is convinced of its practicality and power, but also bel ieves that considerable skill is required to activate an ongoing process of collaboration. For example, practitioners often need preparatory training in order to 
Cognitively internalize the design process as a discrete series of workable steps,

Ontegrate diverse participants and ideas in each step, and

Transfer and apply the obtained findings to their daily problems.

Further in addition, our experience suggests that timely supports from outside network of extremely creative catalytic consultants are indispensable to sustain such a massive coordinative drive and energy over a long period of time. Similar networks are being built by many organizations, including the Enterprise Integration (EI) Community by IFAC/IFIP Task Force on Architectures for Enterprise Integration, of which the author is a member. These electronic and human communities will increase in scale, number and quality by sharing their resources not only for the creation of architectures for enterprise integration but also for the infrastructure itself. (Finger 1993)

\section{REFERENCES}

Bolan, R.B. (1980) The Practitioner as Theorist.Journal of the American Planning Association, vol.46 no.4, 261-274

Checkland, P.B. (1981) Systems Thinking, Systems Practice. John Wiley \& Sons Dixon, J.R. (1993) Impact on Design Research. Proceedings of the 1st International Symposium on Research into Artifacts, Univ. of Tokyo, 12-15

Drucker, P.F. (1991) The Emerging Theory of Manufacturing. Harvard Business Review, May-June, 94-102

Dumas, A. (1993) Re-evaluating the Nature of Designing. NISTEP International Workshop on the creation of Organizational Knowledge, Science and Technology Agency of Japan, 103-139

Finger, S. (1993) Systematization of Knowledge about the Life-Cycle of Artifacts. Proceedings of the 1st International Symposium on Research into Artifacts, Univ. of Tokyo, 91-94

Friedmann, J. (1973) Retracking America. Anchor Press/Doubleday

Inagaki, K. (1993) The Role of Information Systems Infrastructure in Production Management. In: Design of Information Infrastructure Systems for Manufacturing (Goossenaerts J and Yoshikawa H, Eds.), North-Holland, 195-207

Katzy, R.B. et al. (1993) CIMOSA Pilot Implementation for Technology Transfer. In: Design of Information Infrastructure Systems for Manufacturing (Goossenaerts, J. and Yoshikawa, H., Eds.), North-Holland, 25-236

Koestler, A. (1967) The Ghost in the Machine. Hutchinson, London

Kurosu, N. (1992) Production Control in Toyota Motor Corp. (in Japanese), Communications of the Operations Research Society of Japan, vol.37 no.10, 471-479

Mitroff, I.I. and Kilmann, R.H. (1975) On Evaluating Scientific Research: The Contribution of the Psychology of Science.Technological Forecasting and Social Change, vol.8, 163-174

Mitroff, I.I., Barabba, V.P. and Kilmann, R.H. (1977) The Application of Behavioral and Philosophical Technologies to Strategic Planning: A Case Study of a Large Federal Agency. Management Science, vol.4 no.1, 44-58

Nell, J.G. (1996) Architectures and Frameworks. http://www.nist.gov/sc5wg1/arch-fw.htm Ozbekhan, H. (1974) Thoughts on the Emerging Methodology of Planning. In: Systems and Management Annual (Ackoff, R.L., Ed.), Petrocelli Books, New York 
Petrella, R. (1989) Competitiveness for What? Preface to Cooley, M. et al.: European Competitiveness in the 21st Century. Commission of the European Communities

Reich, R. (1991) The Work of Nations. Alfred A. Knopf

Reich, Y., Konda, S.L., Monarch, I.A., Levy, S.N. and Subrahmanian, E. (1996) Varieties and issues of participation and design. Design Studies. vol.17, 165-180

Ryle, G. (1949) The Concept of Mind. London, Hutchinson

Shibata, Y. (1984) Toward a Policy Guidance System for Complex Innovation. In: R\&D Management Systems in Japanese Industry (Eto, H. and Matsui, K., Eds.), North-Holland, 29-57

Shibata, Y. (1992) Toward a Concept of Meta-game, In Crookall, E. and Arai, K. (Eds.) Global Interdependence-- Simulation and Gaming Perspectives. Springer, Berlin, 49-56

Shibata, Y. and Sumita, T. (1993) A Framework of Intellectual Infrastructure for Complex Product Realization. In: Design of Information Infrastructure Systems for Manufacturing (Goossenaerts, J. and Yoshikawa, H. Eds.), North-Holland, 253-264

Tichy, N.M and Sherman, S. (1994) Control Your Destiny or Someone Else Will. Harper, New York

Tomiyama, T. (1993) Artifactual Engineering and the Post Mass Production Paradigm.

Proceedings of the 1st International Symposium on Research into Artifacts, Univ. of Tokyo, 16-23

Williams, C. et al. (1973) Planning and Evaluations Assistance to the NSF Experimental R \&

D Incentives Program, Contract URU-72-66, SRI Project 2291, SRI International

Williams, T.J. et al. (1993) Architectures for Integrating Manufacturing Acti vities and

Enterprises. In: Design of Information Infrastructure Systems for Manufacturing

(Goossenaerts J and Yoshikawa H, Eds.), North-Holland, 3-18

Williams, T.J. (1994) Development of Generic Enterprise Reference Architectures and

Enterprise Integration Methodologies--A Report of the Meeting of the Task Force on

Architectures for Enterprise Inte gration Internal Memorandum of the IFAC/IFIP Task

Force, Vienna Austria, June

Williams, T.J. and Li, H. (1995) A Specification and Statement of Requirements for GERAM

(The Generalized Enterprise Reference Architecture and Methodology). Purdue University

Yoshikawa, H. (1992) Proposal of Artifactual Engineering (in Japanese), Illume, a TEPCO

semiannual review, vol.4 No.1, Feb., Tokyo Electric Power Co., 41-56

Yoshikawa, H. (1993) Intelligent Manufacturing Systems: Technical Cooperation That

Transcends Cultural Differences. In: Design of Information Infrastructure Systems for

Manufacturing (Goossenaerts, J. and Yoshikawa, H., Eds.), North-Holland, 19-40

\section{BIOGRAPHY}

Yusaku Shibata has been hooked on complex problem solving for more than forty years, mainly as an engineering/management staff of Hitachi, Ltd. Now, he is trying to apply his life long experience to global problems such as future generation manufacturing systems planning in the developed regions and local social development planning in the developing regions. He is members of the IFAC/IFIP Task Force on Architectures for Enterprise Integration, the Operations Research Society of Japan, the Japanese Society of Organizational Science and the World Future Society. 